\title{
AN ADAPTIVE POWER SYSTEM STABILIZER BASED ON FOCUSED TIME DELAY NEURAL NETWORK
}

\author{
Widi Aribowo \\ Fakultas Teknik \\ Universitas Negeri Surabaya \\ Email: widiaribowo@unesa.ac.id
}

\begin{abstract}
ABSTRAK
Dalam penelitian ini, algoritma Focused Time-Delay Neural Network (FTDNN) digunakan mengontrol parameter power system stabilizer untuk menemukan kondisi yang dapat diandalkan. The FTDNN PSS diaplikasikan untuk mengurangi overshoot osilasi kecepatan di Single Machine Infinite BUS (SMIB) Dalam kasus prediksi dan kontrol, ada dua metode yang diusulkan dalam penelitian ini. Yang pertama adalah identifikasi dinamika sistem. Berikutnya adalah unit pengoptimalan yang diharapkan untuk meminimalkan gangguan. Kinerja sistem dengan menggunakan pengontrol FTDNN-PSS dibandingkan dengan PSS Konvensional (C-PSS), RNN-PSS dan DTDNN PSS. Hasilnya menunjukkan keefektifan desain FTDNN-PSS, dan keunggulan untuk peningkatan stabilitas sistem tenaga dibandingkan dengan PSS Konvensional pada kasus yang berbeda..
\end{abstract}

Keywords: FTDNN; PSS; RNN; SMIB; Single machine infinite bus.

\begin{abstract}
In this paper, a Focused Time-Delay Neural Network (FTDNN) algorithm was used to control the power system stabilizer parameters to find the reliable conditions. The FTDNN PSS was applied to decrease overshoot of speed oscillation at single machine infinite bus (SMIB). In case of prediction and control, two individual strategies are concerned for the current projects. The first is identification the dynamics of system. The other is an optimization unit expected for minimization disturbances. The performance of the system with FTDNN-PSS controller is compared with a Conventional PSS (C-PSS), RNN-PSS and DTDNN PSS. The results show the effectiveness of FTDNN-PSS design, and superior robust performance for enhancement power system stability compared to Conventional PSS with different cases.
\end{abstract}

Keywords: DTDNN; FTDNN; PSS; SMIB; Single Machine Infinite BUS. 


\section{INTRODUCTION}

A steady state power system may someday be subject to interference. The disturbances are caused by switching operations, discharged power plants, sudden loading, short circuit and others that can disrupt the balance between mechanical inputs and power plant output. This will affect the stability of the plant and may result in less system synchronization.

Power system networks are not only the largest but also the most complicated systems ever devised by human being and getting more sophisticated with the increase of electricity demand. The interconnected power system networks are continually going through different types of disturbances ranging from load-generation mismatches to different types of faults. Generally, the regular disturbances to the networks lead to lowfrequency oscillations $(0.2-2.5 \mathrm{~Hz})$, commonly known as electromechanical oscillations which may become very dangerous to the system by leading towards system blackout.

According To Kundur (1994), To maintain the system stability after being subjected to any kind of disturbances generators are equipped with power system stabilizers(PSS). The main purpose of PSS is to enhance system stability by damping out the unwanted oscillations by generating control signal through excitation system of the generators. According To Karthikeyan and Lakshmi (2012), PSS uses the principle of phase compensation technique to tune its parameters to provide proper damping.

The basic function of PSS is to extend the limits of stability by controlling the excitation of the generator to provide damping to rotor oscillations (synchronous machines), especially for interconnected machines (for multimachine systems). These particular oscillations occur within the range of about $0-2.2 \mathrm{~Hz}$. Power system stabilizers (PSS) must be able to supply suitable stabilization signals over a wide range of operating conditions and perturbations. With the increase in electric power demand and need to command the system at a faster and great flexible way in the com- petitive situation, current power systems can reach stressed conditions less difficult than the last years. The sudden disturbance causes the unstable system or weakly damped oscillations that have been noticed more often in electrical power systems around the world.

Neural networks can easily represent non-linear relationships between input data and output data. Even if the data is incomplete, neural networks are able to correctly classify the different data classes captured from the network or other sources. This has a lot of applicated in such disparate areas as forecasting in wheather, forecasting in financial market, speech recognition, and even the image processing. But static (feed forward) networks have no feedback elements and contain no delays; the output is calculated directly from the input through feed forward connections.

The modeling of the human network system into a mathematical model in the form of a neural network is based on several assumptions: (1) Information processing occurs on simple processor elements called neurons. (2) Signals are passed between the neurons through a link. (3) Each link has a certain weighing, with the signal sent back. (4) Each neuron has an activation function (non-linear) to the inputs to produce an output signal. Characteristics of Neural Network is determined by: (a) The pattern of connection between neurons (architecture), (b) Method of weighting (training or learning algorithms), (c) Activation function.

The weakness of the backpropagation neural network is the limited function of static training and output depends only on current input conditions, so it can not afford. If there is any change of input data pattern.

A PSS is generally consisting of amplifier gain, lead-lag compensation element, and limiter. Though conventional PSS uses different constant numbers for the parameters of PSS, but some of intelligent method have been proposed in the literature to optimal design of the PSS. The intelligent methods are becoming popular because of their robustness and better performances that the 
techniques are complete. Genetic algorithm (GA), a well-known evolutionary algorithm is employed for optimal PSS design to reduce system instability by generating proper control signal. Artificial Neural Network with feed forward method is used to control of PSS parameter. Swarm intelligence technique like particle swarm optimization (PSO) is also used to design PSS in order to damp out the unwanted oscillations. Artificial bee colony $(\mathrm{ABC})$, another intelligent technique is also used to design optimal PSS to enhance power system stabil-ity by suppressing the electromechanical oscillations as reported in Ravi and Duraiswamy (2012) and Eslami et al.(2013). Some hybrid techniques are also used in designing optimal PSS. In previous work, Aribowo (2009) used recurrent neural network to design PSS. RNN PSS has a weakness that is the training time is an average of 2 minute and the interation is an average of 50 from 1000. In this work, FTDNN PSS was applied (simulated with MATLAB software) on a single machine system. The application of FTDNN PSS on a single machine system is emphasized on FTDNN PSS performance against low frequency oscillations and improved system performance.

\section{Method}

FTDNN topology is investigated and tested to use in Overshoot prediction and system optimation. The Overshot Of the Speed are tracked by the dynamic nature of the FTDNN topology. FTDNN is a class of dynamic
ANNs which consists of a feed forward structure with a tapped delay line at the input. FTDNN was developed mainly for processing temporal patterns. The tapped delay lines in the structure help in predicting and controling efficiently.

In dynamic networks, the output depends not only on the current input to the network, but also on the current or previous inputs, outputs, delayed versions or states of the network. Thus, the dynamic network can retain contextual portion of the signals in the local memory available in form of the tapped delay lines.

Although FTDNN are difficult to train, they are generally more powerful than static networks. Sequential or time-varying patterns are trained to learning. As FTDNN have memory, they can be trained to perform systems also. Dynamic networks can be trained using the same gradient-based algorithms that are used for static networks. The error surfaces for FTDNN networks are complex than those for static networks. To obtain an optimal result training of FTDNN requires several iterations. Otherwise training is more likely to be trapped in local minima.

One nice feature of the FTDNN is that it does not require dynamic backpropagation to compute the network gradient. This is because the tapped delay line appears only at the input of the network, and contains no feedback loops or adjustable parameters. For this reason, you will find that this network trains faster than other dynamic networks.

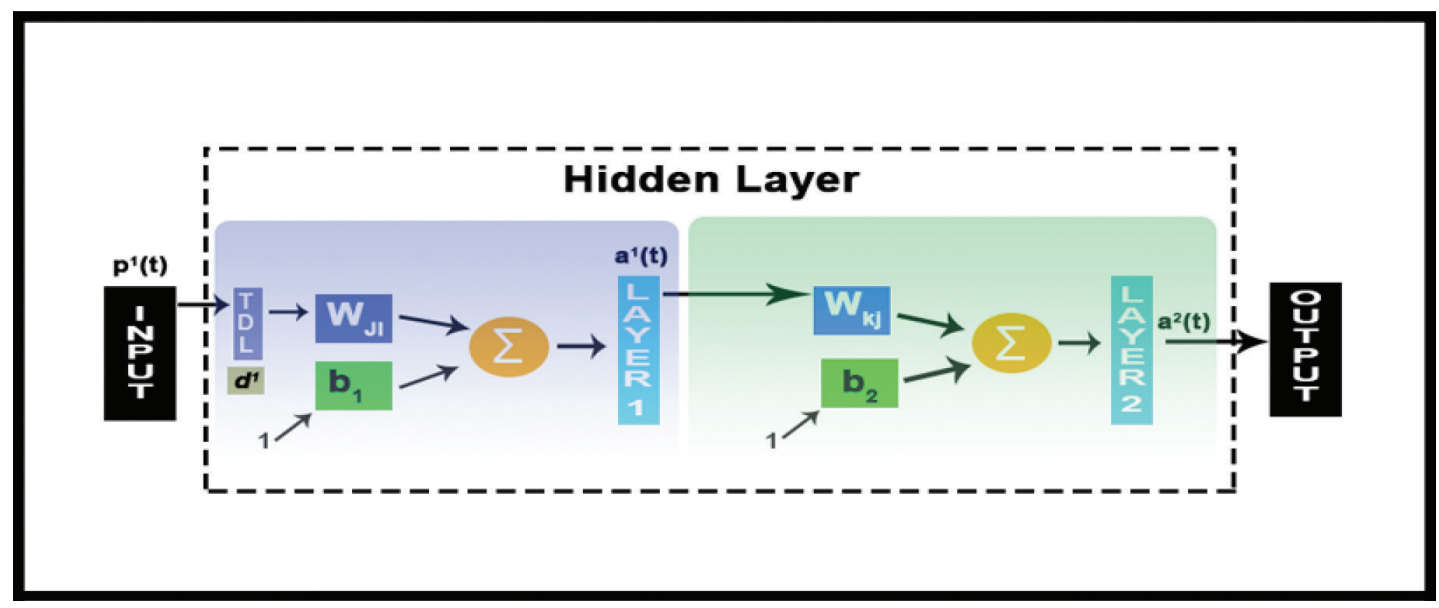

Figure. 1. Proposed Focused Time Delay Neural Network Structure. 


\begin{tabular}{|c|c|c|c|c|c|}
\hline Inaput Node & 703 & $\begin{array}{l}\text { Number Of } \\
\text { Layer }\end{array}$ & 5 & Output Node & 703 \\
\hline Learning Rate & 0.1 & Epoch & $\frac{16 \text { Interation From }}{1000}$ & $\begin{array}{l}\text { Performance } \\
\text { mean } \\
\text { squared error }\end{array}$ & 0.0059 \\
\hline Momentum & 0.2 & Time & 0:00:03 & $\begin{array}{l}\text { Transfer } \\
\text { function for } \\
\text { hidden layer }\end{array}$ & $\begin{array}{c}\text { Hyperbolic } \\
\text { tangent sigmoid } \\
\text { transfer function } \\
\text { (tansig) }\end{array}$ \\
\hline $\begin{array}{l}\text { Transfer } \\
\text { function for } \\
\text { output layer }\end{array}$ & $\begin{array}{l}\text { Linear transfer } \\
\text { function } \\
\text { (purelin) }\end{array}$ & $\begin{array}{l}\text { Network } \\
\text { training } \\
\text { function }\end{array}$ & $\begin{array}{l}\text { Levenberg Marquardt } \\
\text { backpropagation } \\
\text { (trainlm) }\end{array}$ & $\begin{array}{l}\text { Weight/bias } \\
\text { function }\end{array}$ & $\begin{array}{l}\text { Gradient } \\
\text { descent with } \\
\text { momentum } \\
\text { (learngdm) }\end{array}$ \\
\hline
\end{tabular}

Figure. 1. Proposed Focused Time Delay Neural Network Structure.

The equation for a network is Layer 1

$a^{1}(t)=\sum_{i=1}^{j} W_{j i} p^{1}\left(t-d^{1}\right)+b^{1}$

Layer 2

$a^{2}(t)=\sum_{i=1}^{k} W_{k j} a^{1}(t)+b^{2}$

Symbol $\mathrm{j}$ and $\mathrm{k}$ are indicated $\mathrm{j}$ and $\mathrm{k}$ neuron. Where $W_{j i}$ is the network weighted input. In layer $1, p^{1}\left(t-d^{1}\right)$ inputs at the time $\left(t-d^{1}\right) \cdot a^{1}(t)$ is the output from the hidden node; $W_{k j}$ and $(t)$ are the weight and delay connecting in the layer 2. $a^{2}(t)$ is the output of the $k$ th neuron in the $l$ th layer at the time $(t)$.

\section{RESULTS AND DISCUSSION}

The FTDNN identify the output of the plant and try to control the overshoot of the output system by comparing the output of the system with the FTDNN output. If there is deviation error, the error signal is sent back to FTDNN for the learning process to minimize error. FTDNN has two inputs $\Delta \omega$ and $\Delta \mathrm{u} . \Delta \omega$ is the output of the system and $\Delta \mathrm{u}$ is the output of PSS, as the initial input FTDNN uses the output from conventional PSS for the trainning process. Mathematically can be written:
$X i(t)=[\Delta \omega, \Delta u]$

$\Delta \omega$ taken from the rated value of the last synchronous machine which is censored with a constant time interval of $100 \mathrm{~ms}$. $\Delta \mathrm{u}$ is is taken from the last control that has been done using conventional pss. (C-PSS simulation). $\mathrm{T}$ is the sampling period, $\omega$ is the deviation of the angular velocity against the sync speed in $\mathrm{rad} / \mathrm{s} . \mathrm{u}$ is the output of the controller. The network structure used in this training consists of three layers, namely the input layer, the hidden layer and the output layer After the mapping process is done, the next step is to install FTDNN PSS in the system.

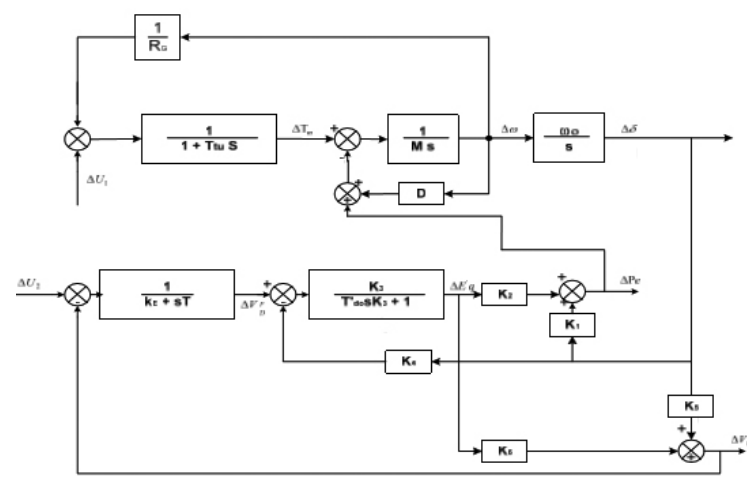

Figure 2. Single Machine Block Diagram [5].

The generator is modeled in the form of Heffron-Philips model, and can be seen in Figure 2. The training data to damp the speed oscillation is data of the output sys- 
tem in the form of speed with variation of the distrubance between 0.5 and $1.0 \mathrm{pu}$. In this study loading is assumed to be: $\mathrm{P}=1.0 \mathrm{pu}$; $\mathrm{Vt}=1.0 \mathrm{pu} ; \mathrm{Pf}=0.85 \mathrm{pu}$, and $\mathrm{P}=0.5 \mathrm{pu} ; \mathrm{Vt}=$ $1.0 \mathrm{pu} ; \mathrm{Pf}=0.85 \mathrm{pu}$. The disruption of $1 \mathrm{p} . \mathrm{u}$ is injected into the system, and a output for the plant as shown in Figure 3 is obtained.

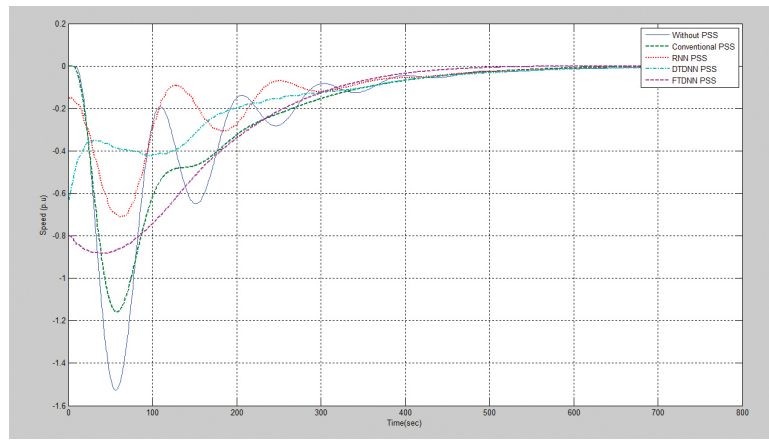

Figure 3. Speed in the nominal operating condition following disturbance 1 (p.u) with conventional PSS, RNN PSS, DTDNN PSS And FTDNN PSS

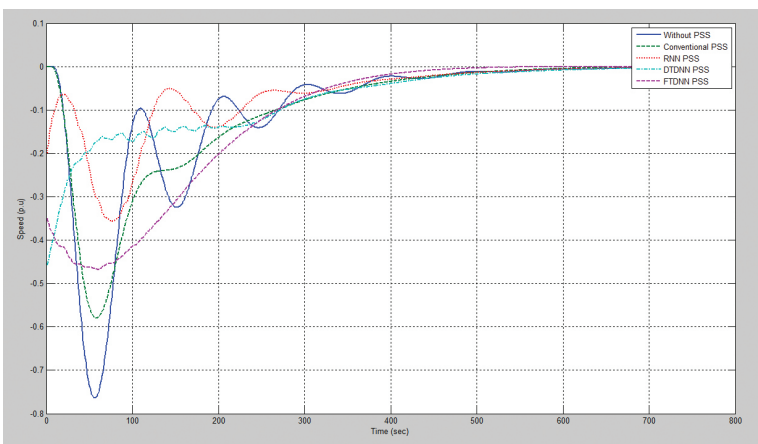

Figure 4. Speed in the nominal operating condition following disturbance 0.5 (p.u) ) with conventional PSS, RNN PSS, DTDNN PSS And FTDNN PSS

FTDNN PSS can decrease the overshoot speed to 0.887 p.u from its original state of 1.519 p.u and better than Conventional PSS which can only decrease by 1.15 p.u. In Figure 4, FTDNN PSS can decrease the overshoot speed to 0.467 p.u from its original state of 0.763 p.u and better than conventional PSS which can only decrease by 0.579 p.u. FTDNN PSS is same value with DTDNN PSS in this case.

\section{CONCLUSION}

In this paper, we presented FTDNN PSS implementations for the Single Machine. FTDNN PSS is able to improve the performance of the Single Machine system in which FTDNN PSS is installed.

The research result shown the proposed FTDNN-PSS design can provide better results as compared to Conventional PSS. It has better control performance. Also, we have shown that PSS based FTDNN-PSS is better for robust power system stabilizer to improve power system under disturbances compared to Conventional PSS in two cases. The comparison between RNN-PSS and FTDNN-PSS shows that RNN-PSS has better damping results. RNN-PSS can reduce the overshoot to 0.65 p.u at load 1 p.u load and 0.34 p.u at load 0.5 p.u. But the training time and interaction of FTDNN is better than RNN-pss.

The success of the design of Focused Time-Delay Neural Network power system stabilizers (FTDNN PSS) is highly dependent on the data and the correct learning process

\section{ACKNOWLEDGEMENTS}

This Work was Supported by Departement Of Electrical engineering, Faculty Of Engineering, State University Of Surabaya. We would like to present our thanks to anonymous reviewers for their helpful suggestions

\section{BIBLIOGRAPHY}

Kundur P, Balu NJ, Lauby MG. 1994. Power system stability and control. New York: McGraw-Hill.

Sauer P, Pai M. 1998. Power system dynamics and stability. Upper Saddle River, NJ: Prentice-Hall.

K. Karthikeyan, P. Lakshmi. 2012. “Optimal Design of PID Controller for Improving Rotor Angle Stability using $\mathrm{BBO}^{\prime \prime}$.Procedia Engineering, 38:889-902.

Ibrahim, L. M. 2010. “Anomaly network intrusion detection system based on distributed time-delay neural network (DTDNN)". Journal of 
Engineering Science and Technology, 5:457-471.

Aribowo,W. 2010. “Stabilisator Sistem Tenaga Berbasis Jaringan Syaraf Tiruan Berulang Untuk Sistem Mesin Tunggal". Journal Of Telecommunication, Computing, Electronics and Control, Vol 8,No 1: 65-72. http://dx.doi.org/10.12928/ telkomnika.v8i1.606.

Machowski, J., Bialek, J.W., Bumby, James R., (1998). "Power System Dynamics and Stability. John Wiley.

Kharrazi,A.(2015)."ArtificialNeuralNetwork Based Power System Stabilizer on a Single Machine Infinite Bus System Modelled in Digsilent Powerfactory and Matlab". Electrical Engineering: An International Journal (EEIJ).2:111.

Gandhi, P.R., Joshi, S.K., (2013). "GA and ANFIS based power system stabilizer". IEEE Power \& Energy Society General Meeting. IEEE, 1-5.

Alkhatib, H., Duveau, J., (2013). “Dynamic genetic algorithms for robust design of multimachine power system stabilizers". Int. J. Electr. Power EnergySyst. 45 (1): 242-251.

Safari, A., 2013. "A PSO procedure for a coordinated tuning of power system stabilizers for multiple operating conditions". J. Appl. Res. Technol. 11(5): 665-673.

Ravi, V. , Duraiswamy, K., (2012). "Effective optimization technique for power system stabilization using Artificial Bee Colony". In: InternationalConference on Computer Communication and Informatics. IEEE, January, pp. 1-6.

Eslami, M., Shareef, H., Khajehzadeh, M., (2013). "Optimal design of damping controllers using a new hybrid artificial bee colony algorithm". Int. J.Electr. Power Energy Syst. 52, 4254 .
Shafiullah, Rana J, Alam S, Abido.(2017). "Online tuning of power system stabilizer employing genetic programming for stability enhancement". Journal of Electrical Systems and Information Technology.204:1-12. https://doi. org/10.1016/j.jesit.2018.03.007

MATLAB 7.6.0 (R2008a) Neural Network Toolbox Software.

Olaru, A., Olaru, S., Paune, D., Oprean, A. 2011. "Optimisation Of The Space Control Trajectory With Proper Neural Network And Lab View Instrumentation". HARVEX 2011 Proceeding, ISSN 1454 - 8003. 167191.

$\mathrm{Xu}$ D, and He R. 2002. "ANN Based Multiple Power System Stabilizers Adaptive and Coordinates Control". PowerCon 2002. International Conference Proceeding. 2002; 1: 361364.

Chen CJ, Chen TC. 2007. “Design of a Power System Stabilizer using a New Recurrent Network". International Journal of Innovative Computing, Information and Control, 3(4): 907918.

You R, Eghbali HJ, Nehrir M. 2003. “An Online Adaptive Neuro-Fuzzy Power System Stabilizer for Multimachine Systems". IEEE Transaction on Power Systems.18(1): 128-135.

Chaturvedi DK, Malik OP. 2004. "Neural Network Controller for Power System Stabilizer". Journal of the Institution of Engineers. 85(1): 138145.

Lin CH. 2004." Adaptive Recurrent Fuzzy Neural Network Control for Synchronous Reluctance Motor Servo Drive". IEE Proc. Power Applications.151(6): 711-724. https://doi.org/10.1049/ipepa:20040687 
J. He and O. P. Malik.1997. “An Adaptive Power System Stabilizer Based on Recurrent Neural Networks", IEEE Trans. Energy Conversion, Vol. 12, No. 4, ,pp.413-419

Olaru, A., Olaru S., Ciupitu, L. 2010. “Assisted research of the neural network by bach propagation algorithm". OPTIROB 2010 International Conference, Calimanesti, Romania, The RPS Singapore Book, pp. 194200.

Sambariya, K.D \& Prasad, R. (2015), “Optimal tuning of fuzzy logic power system stabilizer using harmony search algorithm", Int. J. Fuzzy Syst. 17 (3) :457-470.

Chaib, L., Choucha. A. \& Arif. A. (2017). "Optimal design and tuning of novel fractional order PID power system stabilizer using a new metaheuristic Bat algorithm". Ain Shams Engineering Journal.8:113-125.

Gruning, A \& Sander, M.B. (2014). “Spiking Neural Networks: Principles and Challenges, proceedings of European Symposium on Artificial Neural Networks", Computational Intelligence and Machine Learning. Bruges (Belgium), 23-25.

Ozerdem,C.O., Olaniyi,O.E. \& Oyedotun,K.O. (2017). "Short term load forecasting using particle swarm optimization neural network", 9th International Conference on Theory and Application of Soft Computing, Computing with Words and Perception, ICSCCW. Budapest (hungary),382-393. 